The Egyptian Journal of Hospital Medicine (October 2018) Vol. 73 (1), Page 5777-5782

\title{
The Prevalence of Musculoskeletal Disorders among EMS Personnel in Saudi Arabia, Riyadh \\ ${ }^{1}$ Nawfal Aljerian, ${ }^{2}$ Saud Alshehri, ${ }^{2}$ Emad Masudi, ${ }^{3}$ Abdulaziz Mohammad Albawardi, ${ }^{1}$ Fiasal Alzahrani, ${ }^{2}$ Radhi Alanazi
}

${ }^{1}$ King Abdulaziz Medical City- Riyadh, ${ }^{2}$ King Saud Bin Abdulaziz University, ${ }^{3}$ King Saud Bin Abdulaziz University

\begin{abstract}
Background: Musculoskeletal disorders (MSDs) are common among EMS personnel throughout the world. Objective: The aim of the study was to determine how common the (MSD) among the EMS personnel and its associated factors such as smoking, BMI and place of work (field-workers and hospital-workers) in Saudi Arabia, Riyadh.

Methods: Cross-sectional study to measure the prevalence of (MSD) among the EMS personnel. The Nordic Musculoskeletal Disorders Questionnaires were distributed to collect the data from SRCA and tertiary hospitals. The required sample size was 180 from each group. Chi-square test was used to assess the association between the MSDs and categorical date.
\end{abstract}

Results: Questionnaires of 360 participants were completed and analyzed. The most prevalent site affected was the lower back $(60.3 \%)$ followed by knees $(41.4 \%)$, neck $(40.3 \%)$ and upper back $(40 \%)$; the least frequent disorder was that of hip/thigh (10.3\%). Hence, $(37.2 \%)$ of the paramedics suffer low back pain during their duty. Also, BMI results have shown a prevalence of obesity $(19.2 \%)$, overweight $(41.4 \%)$ and only $(36.1 \%)$ fall within the normal range of $\mathrm{BMI}$ and increased BMI is highly associated to lower back $(\mathrm{p}=0.009)$. Furthermore, smokers number were very high $(65 \%)$ and it was associated with MSD with $(\mathrm{P}<0.05)$ in the lower back and knees. The result showed that there was no significant difference between work places.

Conclusion: The very high prevalence of MSDs was found among paramedics. It is suggested that paramedics have to be engaged in programs at their work place. Such as, exercise, improve the manual handling techniques and encourage smoke cessation.

Keywords: EMS Personnel, Musculoskeletal Disorders; Prevalence; Back Pain; Paramedics; Occupational Disorders; Work-Related Injuries.

\section{INTRODUCTION}

Musculoskeletal disorders (MSDs) comprise a wide range of conditions that affect muscles, tendons, ligaments, joints, bones, peripheral nerves and blood vessels leading to pain, discomfort and impaired mobility ${ }^{(\mathbf{1})}$. MSDs incur a significant economic burden on governments and ministries of health, particularly in terms of costs, reduced productivity, increased disability and absenteeism in both developed and developing countries ${ }^{(2-3)}$. A study done in Baskent University, Turkey, found that the MSDs are common in hospital workers and the most common group was the nurses ${ }^{(4)}$.

Emergency Medical Services (EMS) personnel are a group of health care professional which the job requires to intervene and rescue emergency ill patients as efficiently and quickly as possible, and they work day/night shifts with 12 hours per shift. Work-related musculoskeletal disorders (WRMSDs) are defined as any musculoskeletal disorders that occur during work or resulted from work-related events ${ }^{(5)}$. A systemic review measured the health status among the emergency medical services (EMS) personnel, the study found that EMS personnel are at higher risk of medical impairment and early retirement on medical grounds than the general worker and worker in medical occupations, and the study revealed that they have higher "somatic health problems" (e.g. MSDs) than general workers ${ }^{(6)}$. A study reported that EMS personnel have a high body mass index (BMI), which showed that over $75 \%$ of them where overweight or obese due to busy work schedule and lack of exercise (7). Obesity is highly associated with MSDs such as (low back pain, carpal tunnel syndrome, and plantar fasciitis) ${ }^{(8)}$. Smoking cigarettes also has a negative influence on musculoskeletal system such as intervertebral disc degeneration, muscle pain, tendon rupture, delays fracture healing, and it is highly related to back pain ${ }^{(9)}$. A recent study found the prevalence of MSDs among the EMS personnel have not changed since 1990s and more than $50 \%$ of them complain of musculoskeletal pain and discomfort at least one day in a year ${ }^{(\mathbf{1 0})}$; it seems to be the main reason behind the early retirement among the EMS personnel ${ }^{(11)}$. EMS personnel (EMT or Paramedics) are at higher risk of back pain due to nature of the emergency duty, they are manual handling (lifting, moving and extricating from vehicles) the patients and equipment, facing stressful environments and long- time standing, 
additionally, they also work under abnormal conditions (e.g. scene time, carrying heavy equipment, disasters, with small and confined space inside the ambulance) ${ }^{(12-13)}$. The National Association of Emergency Medical Technicians (NAEMTs), USA, conducted a study on 1,356 EMS personnel and they found that about $47 \%$ of them suffering from back pain while performing their job ${ }^{(14)}$, and the cost related to MSDs' treatment may be high for the EMS personnel and the employer. The study aimed at identifying the prevalence of MSDs among the EMS personnel and its association to years of experience, smoking, exercise, body mass index (BMI), and place of work (field-workers and hospital-workers).

\section{MATERIALS AND METHODS}

A cross-sectional study was done based on survey to measure the prevalence of musculoskeletal disorders among the EMS personnel in Saudi Arabia, Riyadh. The study areas were Saudi Red Crescent Authority (SRCA) which represents field workers and tertiary hospitals in Riyadh which represents hospital workers EMS personnel. The sample size calculation was based on the comparison between field workers and hospital based workers in terms of the prevalence of having at least one of MSDs. To detect a significant difference between the two groups of at least $15 \%$ (50\% vs. $65 \%)$ with $5 \%$ level of significance and a power of $80 \%$, the required sample size was 180 from each group. A convenient sampling technique was used in this study to select from SRCA and tertiary hospitals' EMS personnel who meet the inclusion and exclusion criteria, dispatchers and non-shift EMS personnel were excluded. The processing of the collected data was done through a self-administered questionnaire which consisted of two parts:

Section A: consist of demographic information of participants including age, weight, height, years of service, place of work, smoker and exercise.

Section B: A well-known validated MSD's Nordic questionnaire (NMQ) which involve the body parts from head, neck, shoulders, elbows, wrists/hands, upper back, low back, hips/thighs, and knees and ankles/feet within the 12-months' period and last 7 days' period, each part has closed - ended answer. The positive response was assigned with ' 1 ' and any negative response was assigned with ' 0 '. The statistical software SPSS version 20 was used for data entry and data analysis. Frequencies and percentages were used for categorical data such as smoking status and MSDs. Mean and standard deviation were used to describe the numerical variable such as age, weight and height. Chi-square test was used to assess the association between the MSDs and categorical demographical data such as smoking status. A test was considered significant if $\mathrm{p}$-value $<0.05$.

\section{RESULT}

The present study included 360 participants, where $50 \%$ of them were field workers and the rest were hospital workers. The majority of them were smokers 234(65\%). $100(27.8 \%)$ of them only were doing exercise while 260(72.2) were not. Near half of the participants were overweight 149(41.4\%), 130(36.1\%) were with normal weight. $69(19.2 \%)$ and $12(3.3 \%)$ were obese and underweight respectively. Most of them $189(52.5 \%)$ have $1-5$ years of services, $119(33.1 \%)$ have $6-10$ years of services, 33(9.2\%) have $11-15$ years of services and only $19(5.3 \%)$ have over 16 years of services. Demographics of the participants are shown in table 1.

\begin{tabular}{|c|c|c|}
\hline \multicolumn{3}{|c|}{ Categorical Data } \\
\hline \multirow{2}{*}{ Place of work } & Field-workers & $180(50 \%)$ \\
\hline & Hospital-workers & $180(50 \%)$ \\
\hline \multirow{2}{*}{ Smoking } & smokers & $234(65 \%)$ \\
\hline & non-smokers & $126(35 \%)$ \\
\hline \multirow{2}{*}{ Exercise } & YES & $100(27.8 \%)$ \\
\hline & $\mathrm{NO}$ & $260(72.2 \%)$ \\
\hline \multirow{4}{*}{ BMI } & under weight & $12(3.3 \%)$ \\
\hline & normal weight & $130(36.1 \%)$ \\
\hline & over weight & $149(41.4 \%)$ \\
\hline & obese & $69(19.2 \%)$ \\
\hline \multirow{4}{*}{ Years of Service } & 5-Jan & $189(52.5 \%)$ \\
\hline & 10-Jun & $119(33.1 \%)$ \\
\hline & 15-Nov & $33(9.2 \%)$ \\
\hline & $16+$ & $19(5.3 \%)$ \\
\hline
\end{tabular}

The prevalence of musculoskeletal disorder among the participants within the last 12 months is shown in figure 1 . Where the highest disorder was in the low back $60.3 \%$, then we found that the illness was $40.3 \%$ in the neck, $41.4 \%$ in the knees, $40 \%$ in the upper back , $33.9 \%$ in the shoulders , $26.1 \%$ in the ankles/feet, $21.4 \%$ in the wrist/hands, $16.7 \%$ in the elbow and $10.3 \%$ in the hip/thigh. 


\section{THE PREVALENCE WITHIN 12 MONTHS}

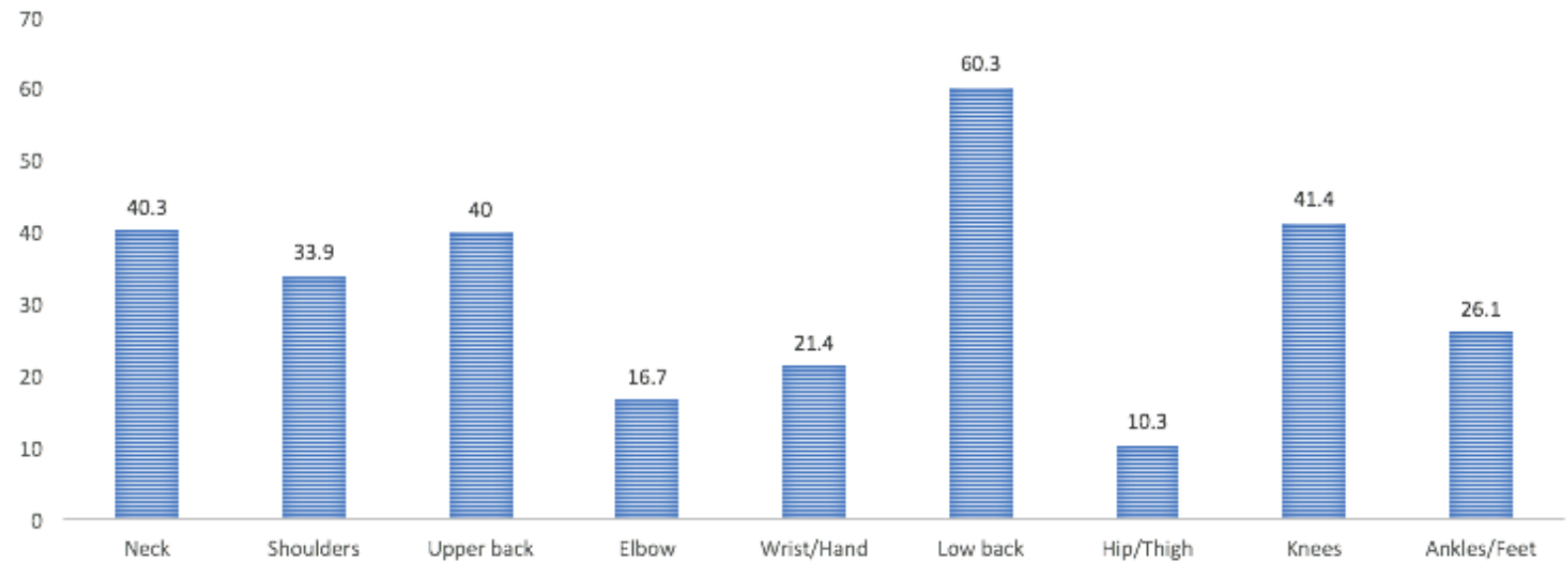

Figure 1: The prevalence of musculoskeletal disorder among the participants within the last 12 months

The prevalence of musculoskeletal disorder among the participants within the last 7 days is shown in figure 2 . Where the highest musculoskeletal disorder was also in the low back $37.2 \%$, then, $22.8 \%$ in the knee, 19.7 in the upper back, $15 \%$ in the ankles/feet, $14.7 \%$ in the shoulders, $8.9 \%$ in the wrist/hands, $6.9 \%$ in the elbow and $5.3 \%$ in the hip/thigh.

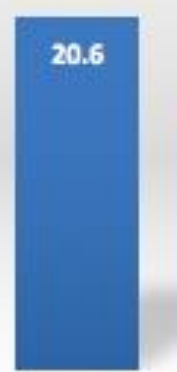

neck

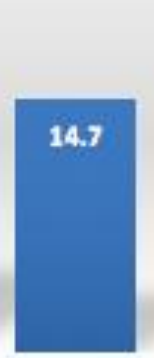

shoulders

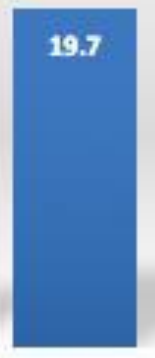

upper back

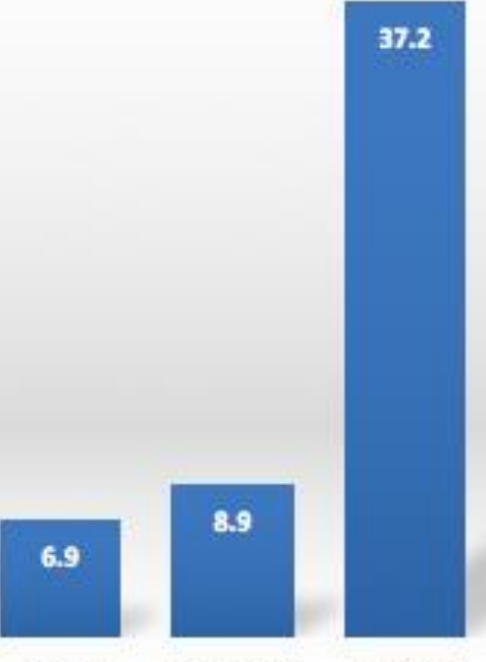

elbow

wrist/hand

low back

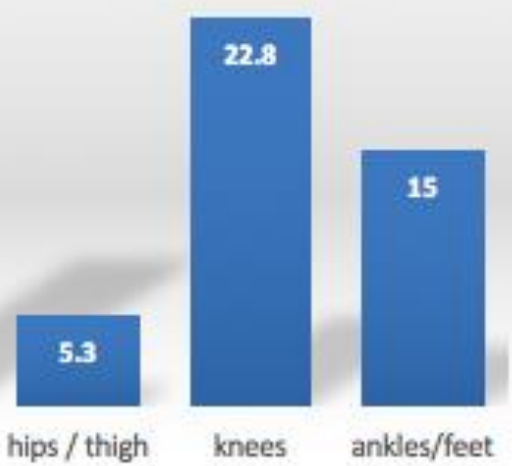

Figure 2: The prevalence of musculoskeletal disorder among the participants within the last 7 days.

The association between smoking and musculoskeletal disorder is shown in table 2. There were two MSDs significantly affected by smoking including upper back $(\mathrm{P}$ value $=0.019)$ and low back $(\mathrm{P}$ value $=0.002)$. The rest MSDs were not significantly affected by smoking $(\mathrm{P}$ value $>0.05)$ 
Table 2: The association between smoking and MSD.

\begin{tabular}{|c|c|c|c|}
\hline \multicolumn{4}{|c|}{ The association between smoking and MSD } \\
\hline & Non-Smokers $\mathrm{n}(\%)$ & Smokers $\quad \mathrm{n}(\%)$ & $P$ value. \\
\hline Neck & $45(35.70 \%)$ & $100(42.70 \%)$ & 0.195 \\
\hline Shoulders & $37(29.40 \%)$ & $85(36.30 \%)$ & 0.183 \\
\hline Upper Back & $40(31.70 \%)$ & $104(44.40 \%)$ & $0.019 *$ \\
\hline Elbow & $22(17.50 \%)$ & $38(16.20 \%)$ & 0.767 \\
\hline Wrist/Hand & $26(20.60 \%)$ & $51(21.80 \%)$ & 0.798 \\
\hline Low Back & $62(49.20 \%)$ & $155(66.20 \%)$ & $0.002 *$ \\
\hline Hips /Thighs & $11(8.70 \%)$ & $26(11.10 \%)$ & 0.478 \\
\hline Knees & $48(38.10 \%)$ & $101(43.20 \%)$ & 0.352 \\
\hline Ankles/Feet & $33(26.20 \%)$ & $61(26.10 \%)$ & 0.980 \\
\hline
\end{tabular}

Table 3 shows the association between the exercise and MSDs where only the elbow is significantly affected by the exercise $(\mathrm{P}$ value $=0.015)$ and the other musculoskeletal disorders is not significant.

Table 3: The association between the exercise and MSDs.

\begin{tabular}{|c|c|c|c|}
\hline \multicolumn{4}{|c|}{ The association between the exercise and MSDs } \\
\hline & No $\mathrm{n}(\%)$ & Yes n(\%) & $P$ value \\
\hline Neck & $110(42.30 \%)$ & $35(35.00 \%)$ & 0.205 \\
\hline Shoulders & $90(34.60 \%)$ & $32(32.00 \%)$ & 0.639 \\
\hline Upper Back & $109(41.90 \%)$ & $35(35.00 \%)$ & 0.230 \\
\hline Elbow & $51(19.60 \%)$ & $9(9.00 \%)$ & $0.015^{*}$ \\
\hline Wrist/Hand & $55(21.20 \%)$ & $22(22.00 \%)$ & 0.861 \\
\hline Low Back & $164(63.10 \%)$ & $53(53.00 \%$ & 0.080 \\
\hline Hips/Thighs & $27(10.40 \%)$ & $10(10.00 \%)$ & 0.914 \\
\hline Knees & $115(44.20 \%)$ & $34(34.00 \%)$ & 0.078 \\
\hline Ankles/Feet & $72(27.70 \%)$ & $22(22.00 \%)$ & 0.271 \\
\hline
\end{tabular}

In table 4, it is evident that there was no significant difference and association between musculoskeletal disorders and the place of work (hospital workers and field workers).

Table 4: The association between place of work and MSDs

\begin{tabular}{|l|l|l|l|}
\hline \multicolumn{4}{|c|}{ The association between place of work and MSDs } \\
\hline & Field $\mathrm{n}(\%)$ & Hospitals $\mathrm{n}(\%)$ & P value \\
\hline Neck & $74(41.1 \%)$ & $71(39.4 \%)$ & 0.747 \\
\hline Shoulders & $57(31.7 \%)$ & $65(36.1 \%)$ & 0.373 \\
\hline Upper Back & $72(40 \%)$ & $72(40 \%)$ & 1.000 \\
\hline Elbow & $32(17.8 \%)$ & $28(15.6 \%)$ & 0.572 \\
\hline Wrist/Hand & $39(21.7 \%)$ & $38(21.1 \%)$ & 0.898 \\
\hline Low Back & $115(63.9 \%)$ & $102(56.7 \%)$ & 0.161 \\
\hline Hips/Thighs & $18(10 \%)$ & $19(10.6 \%)$ & 0.561 \\
\hline Knees & $71(39.4 \%)$ & $78(43.3 \%)$ & 0.454 \\
\hline Ankles/Feet & $40(22.2 \%)$ & $54(30 \%)$ & 0.093 \\
\hline
\end{tabular}

We investigated the association between BMI and MSD. The MSD sites were affected by BMI including the neck $(\mathrm{P}$ value $=0.007)$, and the upper back $(\mathrm{P}$ value 0.004$)$, low back $(\mathrm{P}$ value $=0.009)$ and knees $(\mathrm{P}$ value $=$ $0.001)$. This is shown in table 5 . 
Table 5: The association between BMI and MSDs

\begin{tabular}{|c|c|c|c|c|c|}
\hline \multicolumn{6}{|c|}{ The association between BMI and MSDs. } \\
\hline & Underweight $\mathrm{n}(\%)$ & $\begin{array}{c}\text { Normal } \\
\text { weight } \mathrm{n}(\%)\end{array}$ & $\begin{array}{l}\text { Over weight } \\
\mathrm{n}(\%)\end{array}$ & $\begin{array}{l}\text { Obese } \\
\mathrm{n}(\%)\end{array}$ & $P$ value \\
\hline Neck & $3(25 \%)$ & $42(32.3 \%)$ & $61(40.9 \%)$ & $39(56.5 \%)$ & $0.007^{*}$ \\
\hline Shoulders & $4(33.3 \%)$ & $33(25.4 \%)$ & $57(38.3 \%)$ & $28(40.6 \%)$ & 0.077 \\
\hline Upper Back & $6(50 \%)$ & $42(32.3 \%)$ & $56(37.6 \%)$ & $40(58 \%)$ & $0.004 *$ \\
\hline Elbow & $0(0 \%)$ & $18(13.8 \%)$ & $29(19.5 \%)$ & $13(18.8 \%)$ & 0.239 \\
\hline Wrist/Hand & $2(16.7 \%)$ & $24(18.5 \%)$ & $31(20.8 \%)$ & $20(29 \%)$ & 0.359 \\
\hline Low Back & $4(33.3 \%)$ & $68(52.3 \%)$ & $96(64.4 \%)$ & $49(71 \%)$ & $0.009 *$ \\
\hline Hips/Thighs & $2(16.7 \%)$ & $12(9.2 \%)$ & $15(10.1 \%)$ & $8(11.6 \%)$ & 0.844 \\
\hline Knees & $5(41.7 \%)$ & $33(25.4 \%)$ & $69(46.3 \%)$ & $42(60.9 \%)$ & $0.001 *$ \\
\hline Ankles/Feet & $1(8.3 \%)$ & $26(20 \%)$ & $45(30.2 \%)$ & $22(31.9 \%)$ & 0.0173 \\
\hline
\end{tabular}

Table 6 demonstrates the association between years of service and MSDs where neck, shoulders, upper back, elbow and knees were significantly affected by the years of services $(\mathrm{P}$ value $=0.001),(\mathrm{P}$ value $=0.012),(\mathrm{P}$ value $=0.017),(\mathrm{P}$ value $=0.016)$ and $(\mathrm{P}$ value $=0.001)$ respectively .

Table 6: The association between years of service and MSDs.

\begin{tabular}{|l|l|l|l|l|l|}
\multicolumn{7}{|c|}{ The association between years of service and MSDs } \\
\hline & $1-5$ & $6-10$ & $11-15$ & $16+$ & sig. \\
\hline Neck & $51(27 \%)$ & $61(51.3 \%)$ & $23(69.7 \%)$ & $10(52.6 \%)$ & $.001^{*}$ \\
Shoulders & $51(27 \%)$ & $45(37.8 \%)$ & $16(48.5 \%)$ & $10(52.6 \%)$ & $.012^{*}$ \\
Upper Back & $62(32.8 \%)$ & $57(47.9 \%)$ & $18(54.5 \%)$ & $7(36.8 \%)$ & $.017^{*}$ \\
Elbow & $28(14.8 \%)$ & $17(14.3 \%)$ & $7(21.2 \%)$ & $8(42.1 \%)$ & $.016^{*}$ \\
Wrist/Hand & $40(21.2) \%$ & $22(18.5 \%)$ & $9(27.3 \%)$ & $6(31.6 \%)$ & .484 \\
Low Back & $109(57.7 \%)$ & $73(61.3 \%)$ & $23(69.7 \%)$ & $12(63.2 \%)$ & .597 \\
Hips/Thighs & $20(10.6 \%)$ & $12(10.1 \%)$ & $3(9.1 \%)$ & $2(10.5 \%)$ & .995 \\
Knees & $64(33.9 \%)$ & $50(42 \%)$ & $23(69.7 \%)$ & $12(63.2 \%)$ & $.001^{*}$ \\
Ankles/Feet & $46(24.3 \%)$ & $33(27.7 \%)$ & $11(33.3 \%)$ & $4(21.1 \%)$ & .656 \\
\hline
\end{tabular}

\section{DISCUSSION}

The result of the study showed a very high prevalence of MSDs. The highest was the lower back $(60.3 \%)$, knee $(41.4 \%)$ and the upper back (40\%), and it was common and increased with years of service, smoking and increased BMI. In this study found that $(37.2 \%)$ suffered from the low back pain in their duty. In a study reported that about (47\%) suffering back pain while the performing the job ${ }^{(14)}$. The prevalence of MSDs among Japanese nurses was 85, 5\%; the highest MSD reported was that of shoulder [71,9\%], then lower back [71, 3\%], neck $[54,7 \%]$ and upper back $[33,9 \%]^{(15,16)}$.

The reported smokers were $(65 \%)$ and highly associated with lower and upper back. A study suggests that smoking is associated with the most of MSDs sits and it associated with lower back pain ${ }^{(9)}$. Moreover, smoking cigarettes has negative influence on muscle metabolism (17). EMS is a stressful job; a study reported that there is a link between smoking cigarettes and anxiety ${ }^{(18)}$, and some individual smoke to reduce the negative effects ${ }^{(19)}$.

Most of the participants were overweight (41.4\%), the obesity was (19.2\%) and only (36.1\%) fall within normal weight. A recent study showed a high percentage of EMS personnel and firefighters were considered [77\%] overweight ${ }^{(7)}$. Some studies found that rotating shift worker and those who have long term exposure to circadian misalignment have higher BMI than non-shift workers ${ }^{(20)}$. As it was shown in the results that only $(27.8 \%)$ do exercise, the study suggests that exercise is a protective factor against the MSDs ${ }^{(\mathbf{2 1})}$. The reason behind that EMS personnel tend not to exercise has already discussed and that EMS personnel face busy shifts and 
busy shift schedule ${ }^{(7)}$. The EMS personnel face too many stressors and it is a stressful job ${ }^{(6)}$. Additional study revealed that long time exposure to the stress will increase the BMI ${ }^{(7)}$.

One of the study objectives was to clarify the difference between field-worker and hospital workers as the results revealed that there was difference between them and the MSDs do not associated to the place of work. Also, the MSDs are not difference associated with years of services. The EMTs and paramedic must work efficiently and quickly as they can, also WRMSDs and MSDs are common among EMS personnel and became a health burden for them. A study suggested that the awkward postures such as (bending and twisting) during the job tasks could be a causative to WRMSDs ${ }^{(22)}$. Moreover, the ambulance space and the equipment did not arrange appropriately to let them do their work safely and the most injury occurred while the EMS personnel manual handling the patients ${ }^{(23-24)}$.

\section{CONCLUSION}

The prevalence of musculoskeletal disorders is high. Most of the EMS personnel complain of lower back pain and they are at higher risk of WRMSDs. The BMI is high which escalate the MSDs and they must be engaged in exercise programs. Smoke cession program should be accessible for them. Manual handling technics must be explained to reduce the risk of WRMSDs. .Further researches are in need to assess their awareness about MSDs and WRMSDs.

\section{REFERENCE}

1. Punnett L, Wegman DH(2004): Work-related musculoskeletal disorders: the epidemiologic evidence and the debate. J Electromyogr Kinesiol .,14(1):13-23.

2. Meucci RD, Fassa AG, Faria NM(2015): Prevalence of chronic low back pain: systematic review. Rev Saude Publica. , doi: 10.1590/S0034-8910.2015049005874.

3. Gouveia N, Rodrigues A, Eusebio M, Ramiro S, Machado P, Canhao H et al.(2016): Prevalence and social burden of active chronic low back pain in the adult Portuguese population: results from a national survey. Rheumatol Int.,36:183-97.

4. Karahan A, Kav S, Abbasoglu A, Dogan N(2009): Low back pain: prevalence and associated risk factors among hospital staff. J Adv Nurs. ,65:516-24.

5. Salik Y, Özcan A(2004): Work-related musculoskeletal disorders: a survey of physical therapists in Izmir-Turkey. BMC Musculoskeletal Disord. ,5(1):1. doi: 10.1186/14712474-5-27

6. Sterud T, Ekeberg Ø, Hem E(2006): Health status in the ambulance services: a systematic review. BMC Health Serv Res.,6(1):1.

7. Tsismenakis AJ, Christophi CA, Burress JW, Kinney AM, Kim M, Kales SN(2009): The obesity epidemic and future emergency responders. Obesit.,17(8):1648-50.
8. Anandacoomarasamy A, Caterson I, Sambrook P, Fransen M, March L(2008): The impact of obesity on the musculoskeletal system. Int J Obes (Lond),32(2):211-22.

9. Abate M, Vanni D, Pantalone A, Salini V(2013): Cigarette smoking and musculoskeletal disorders. Muscles Ligaments Tendons J.,3(2):63-9.

10. Arial M, Benoît D, Wild P(2014): Exploring implicit preventive strategies in prehospital emergency workers: A novel approach for preventing back problems. Appl Ergon. ,45(4):1003-9.

11. Rodgers LM(1998): A five year study comparing early retirements on medical grounds in ambulance personnel with those in other groups of health service staff Part II: Causes of retirements. Occup Med (Lond). ,48(2):119-32.

12. Okada N, Ishii N, Nakata M, Nakayama S(2005): Occupational stress among Japanese emergency medical technicians: Hyogo Prefecture. Prehosp Disaster Med.,20(02):115-21.

13. Adib-Hajbaghery M, Zohrehea J(2013): Back pain among paramedics: A pilot study. Nurs Midwifery Stud.,2(2):103-4.

14. Dailey B(2010): Musculoskeletal injury prevention: protect yourself from on the job injuries. J Emerg Med Serv. , Retrieved from http://www.jems.com/article/health-andsafety/muculoskeletal-injury-prevent.

15. Smith DR, Mihashi M, Adachi Y et al.(2006): A detailed analysis of musculoskeletal disorder risk factors among Japanese nurses. J Safety Res. ,37:195-200.

16. Smith DR, Mihashi M, Adachi Y et al.(2009): Menstrual disorders and their influence on low back pain among Japanese nurses. Ind Health ,47:301-12.

17. Rom O, Kaisari S, Aizenbud D, Reznick AZ (2012): Identification of possible cigarette smoke constituents responsible for muscle catabolism. Journal of muscle research and cell motility ,33(3-4):199-208.

18. Battista SR, Stewart SH, Fulton HG, Steeves D, Darredeau C, Gavric D(2008): A further investigation of the relations of anxiety sensitivity to smoking motives. Addictive Behaviors,33(11):1402-8.

19. Comeau N, Stewart SH, Loba $\mathbf{P ( 2 0 0 1 )}$ : The relations of trait anxiety, anxiety sensitivity, and sensation seeking to adolescents' motivations for alcohol, cigarette, and marijuana use. Addictive behaviors.,26(6):803-25.

20. Van Cauter E, Spiegel K, Tasali E et al.(2008): Metabolic consequences of sleep and sleep loss. Sleep Med .,9(1):S23-8.

21. Lee JE, Kim SL, Jung HS, Koo JW, Woo KH, Kim MT(2009): Participatory action oriented training for hospital nurses (PAOTHN) program to prevent musculoskeletal disorders. Journal of occupational health,51(4):370-6.

22. Grayson D, Dale AM, Bohr P, Wolf L, Evanoff $B(2005)$ : Ergonomic evaluation: Part of a treatment protocol for musculoskeletal injuries. Aaohn Journal,53(10):450-7.

23. Fisher TF, Wintermeyer SF(2012): Musculoskeletal disorders in EMS: Creating employee awareness. Professional Safety,57(07):30-4.

24. Maguire BJ, Hunting KL, Guidotti TL, Smith GS(2005): Occupational injuries among emergency medical services personnel. Prehospital Emergency Care,9(4):405-11. 